\section{Support Irish science}

SIR - Researchers in Ireland continue to compete internationally as best they can, but we still lack any coherent long-term policy for the development of basic research. Our industries fail to appreciate the need for highly trained, competent researchers beyond the $\mathrm{PhD}$ qualification. We have failed miserably to inculcate a culture of enterprise and innovation.

In 1994, the Science, Technology and Innovation Advisory Council (STIAC) was set up by the then Minister for Commerce and Technology, Mr Seamus Brennan, to advise government on how best to improve the effectiveness of the national science and technology system in contributing to national economic development. The resulting Tierney Report made 160 individual recommendations that underpinned a series of detailed and wide-ranging measures aimed at generating the dynamism necessary to create a highly competitive economy and to make a significant impact on the problem of unemployment.

The recommendations dealt with issues ranging from increased expenditure on research and development (R\&D) by business to integrated tax measures to stimulate commercial $\mathrm{R} \& \mathrm{D}$, intercompany cooperation programmes, earmarking of funds for new R\&D in both multinational and indigenous companies, funding for $R \& D$ in the food industry, venture-capital funding, technology acquisition and support for patents.

Increased incremental costing over existing base-level expenditure was estimated at I\&42 million for the first year, rising to a plateau of I£82 million after five years. While STIAC recognized that the reallocation of public resources of this magnitude would take time, it recommended an immediate injection of I£25 million to fill the most urgent gaps.

During the second half of 1995, the Travers Task Force examined the STIAC report with a view to advising government on the immediate implementation of the recommendations. The results of this exercise, which had no formal input from the research community, are subject to the Official Secrets Act and have never been published. On 19 March 1996, the current Minister for Commerce, Science and Technology, Mr Pat Rabbitte, announced the allocation of an additional I $£ 4$ million for science and technology in this year's budget to begin implementing the recommendations of the Tierney Report. Any increase in discretionary funding to science and technology is welcome, but the additional funding represents only $10 \%$ of the cost of implementing the first year of the programme.

There is an inherent technological and innovative weakness in small and mediumsized enterprises (SMEs) in Ireland. In terms of R\&D spending, the indigenous sector performs about half as well as its multinational counterparts. About $75 \%$ of the manufacturing companies in Ireland almost by definition indigenous SMEs have only a minimal technological capability. A wonderful opportunity has been missed to launch innovation once and for all and to enable technically qualified young graduates and technicians to begin to inculcate a spirit of innovation within our indigenous SMEs. In the process, many new high-technology skilled jobs might have been created. But the opportunity has been lost because the government, despite having set up an expert group to advise on what needs to be done, has once again failed to make the hard financial decision to implement the programme outlined by the STIAC group. We have instead an $a$ la carte selection of some of the STIAC recommendations, with the If4 million spread thinly over a dozen different initiatives, including technology services and techstart schemes, basic research and hopefully the promotion of the awareness of science, technology and innovation.

In recent years, successive Irish governments have poured large sums of money on an ad hoc basis into arts festivals, the Gaelic Athletic Association, Dublin Zoo, Telefis na Gaeilge and so on. Projects and programmes appear to be funded on the basis of popularity or on the whims of topical or sectoral appeal.

There does not appear to be any collective political will in the Irish government to address the innovation question. If Ireland is serious about meeting the commercial and industrial challenges of the next century, now is the time to begin implementing the Tierney Report. It is time for visionary collective cabinet responsibility, with decisions on science and technology policy being made by elected government representatives and not by anonymous mandarins within the Department of Finance.

\section{J. Fegan}

(Chairman, Irish Research

Scientists Association)

Physics Department,

University College Dublin,

Dublin 4

Ireland

\section{Peace dividend?}

SIR - In the former Soviet Union, students entering the traditional annual Chemistry Contest were usually given tasks that were slightly more difficult than the normal high-school courses. In contrast, this year and last in the Soros Contest, the tasks were based on facts known to most students from their school courses, but which required some additional logical thinking and unusual approaches. There was also a postal round before the main round to help participants to assess the difficulty of the tasks and their own preparedness. When formulating the postalround tasks, facts that might not be generally known were specially explained.

The Soros Contest attracted high-school students from all regions of Russia. About 2,000 students in each of three age groups took part. The object of the contest is to find talented boys and girls irrespective of their mastery of the school curriculum in chemistry. In both the postal round and the main round, some tasks were formulated similarly for neighbouring age groups (9th and 10 th grades, or 10th and 11th grades). In most cases, such tasks were solved significantly better (in some cases twofold) by younger students.

This phenomenon could be interpreted to mean that the number of gifted boys and girls is increasing every year. There must be a reason for such a rise. No significant changes have recently been made in the teaching of chemistry: old textbooks are usually used and there have been even fewer of them.

The explanation seems to be that Russia in recent years has become more 'friendly' for talented people. Boys and girls in 11th grade were born in 1980, those in 9th grade in 1982; their childhood coincided with Gorbachev's perestroika. This is the first generation of children who know nothing of the communist 'pioneer' organization in junior high school, when ideology was controlled by the Communist Party Central Committee. Being able from early childhood to hear and discuss alternative points of view, to suggest hypotheses and try to prove them, to think things over and comprehend them instead of just accepting the only 'true and nonrevisable' theory are probably the advantages that students now in 10th and 11th grades have over the older generations in Russia.

The phenomenon of the development of science in a totalitarian state still needs to be investigated. The sudden fall of communism may have given a spur to the rise in the number of gifted people. If so, we may expect an increase in competition for the right to study at leading technical colleges, and a consequent improvement in students' performance.

There are many young graduates from Russian universities and institutes now working successfully in science and technology in the West. The new generation may be even more productive. Taking into consideration the size of Russia and the potential of leading Russian universities, the influx of new Russian scientists into world science may have a global impact on the development of civilization.

\section{Andrey Nedospasov}

Institute of Molecular Genetics, 123182 Moscow,

\section{Russia}

e-mail: img@glas.apc.org 